\title{
Comparative Analysis of Growth Convergence in Selected West African Countries
}

\author{
Alexandrov Nevski Sachs Semanou (Corresponding author) \\ PhD Candidate, Marmara University, Istanbul \\ E-mail: semsachs01@gmail.com
}

\author{
Kamil Uslu \\ Associate Professor, Marmara University \\ Principal of KAVRAM Vocational School, Istanbul \\ E-mail : Kamil.uslu@gmail.com
}

Received: June 12, 2019 Accepted: June 28, 2019 Published: July 24, 2019

doi:10.5296/ber.v9i3.14910

URL: https://doi.org/10.5296/ber.v9i3.14910

\begin{abstract}
This paper analyses the $\beta$-convergence process of West African countries with a focus on Benin, Côte d'Ivoire, Ghana, and Togo. It has been motivated by the apparent persistence of income gap between West African countries. To achieve the objective of the study, we use both descriptive statistics and econometric approach. The study covers the time period of 27 years (1990-2017). The results show the absence of a unit steady state for the region and do not confirm neoclassical theory's predictions. Rather, it shows the existence of club convergence in West Africa. Also, lower-income countries such as Benin and Togo have lower steady-state income compared to Ghana and Cote d'Ivoire.
\end{abstract}

Keywords: Convergence, Steady State, Economic growth, West Africa

\section{Introduction}

The principle of decreasing returns of capital in Solow-Swan's theory predicts faster growth in poor countries (low level of physical capital) than in rich ones. This process would lead to a catch-up between poor and rich countries in the long run. But later studies seem to contradict the validity of this prediction. The authors of endogenous growth including Romer, Rebelo and King have pointed out that the traditional neoclassical relationship between per capita income and the growth rate and convergence of countries towards a steady state is not 
observed in reality (Islam, 1995). These observations relaunched the debates on convergence. The facts would seem rather to go in the direction of absence of convergence or even presence of divergence between countries; especially between poor and rich countries.

This study focuses on the issue of convergence by taking into account countries with, a priori, the same economic status: West African countries. In fact, West Africa is part of sub-Saharan Africa, one of the regions that almost exclusively includes developing countries. This region, composed of 17 countries $^{1}$, constitute a real economic potentiality with about $40 \%{ }^{2}$ of Sub-Saharan African GDP in 2017 and a population of more than 350 million consumers in 2015 (Wold Development Indicators, WDI 2019). However, the economic performances of most of the countries in this region do not seem to be sufficient to significantly improve people's living conditions. Thus, excepted Cape Verde and Ghana (which are in the group of medium human development countries), all of the countries in the region remain in the group of countries with low level of human development (see UNDP, 2018). Also, the long-awaited convergence between the economies does not seem to be realized. For example, in 2017 Gross Domestic Product (GDP) per capita income in terms of purchasing power parity (PPP) in the region averaged about US\$ 2879.56. In countries such as Nigeria and Ghana, it (GDP per capita PPP) was US\$ 5874.7 and US\$ 4492.32 respectively, while that of Niger and Togo reported to be US\$ 1659.9 and US\$ 1016.6 respectively (WDI, 2019). The presence of countries such as Nigeria (biggest economy in Africa), Cote d'Ivoire and Ghana in the region sharply contrasts with the situation of countries small economies like Niger and Guinea Bissau.

The objective of this study is to analyse income convergence in the West African subregion by focussing on the case of four countries: Benin, Cote d'Ivoire, Ghana and Togo. Specifically, the study aims at making a comparative analysis $\beta$-convergence in the West African region and between the four selected countries. It also, analyses the characteristics of the region and selected countries' steady states. This study shows the importance of per capita income in the process of convergence in the region. This study in addition to analyse the region's convergence dynamic, focuses on the cases of four countries (Benin, Ghana, Cote d'Ivoire and Togo). Indeed, the choice of these four countries is precisely motivated by the fact that, they are neighbouring countries that share many common features. These features include geography (access to the sea, similar climates, proximity with Nigeria), religion, culture and, somehow, institutions. However, a clear difference can be seen in the evolution of per capita incomes in these countries in recent years (see Figure 1). All the studied countries belong either to low or lower middle-income countries group ${ }^{3}$. Ghana and Cote d'Ivoire have higher income levels compared to Benin and Togo. So, it is important to know whether these countries have different convergence rates and steady states.

Many studies have investigated the issue of convergence in West African region (Among

\footnotetext{
${ }^{1}$ Benin, Burkina Faso, Cape Verde, The Gambia, Ghana, Guinea, Guinea-Bissau, Cote d'Ivoire, Liberia, Mali, Mauritania, The Niger, Nigeria, Senegal, Sierra Leone and Togo and Saint Helena, an UK Overseas Territory ${ }^{2}$ Author's calculation using WDI 2019

${ }^{3}$ Except Nigeria, Ghana, Cote d'Ivoire, and Mauritania which belong to lower middle-income countries the other countries are low income countries (The World Bank, 2019).
} 
others, Jones, 2002, Dramani 2014, Bah 2014, 2015). For example, Bah $(2014,2015)$ studied the stochastic convergence and the beta-convergence of $\mathrm{UEMOA}^{4}$ countries by comparing them with the average income level of the zone. Jones (2002), addressed the subject of convergence in ECOWAS $^{5}$ using cross section and time series analysis that allowed comparison of the convergence dynamics of countries taken two by two.

However, these studies do not allow a clear comparison between the steady states of all the different countries. The current study contributes to fil this gap by investigating not only the presence of convergence of different countries or group of countries towards a single steady state, but also analyses (if appropriate) the characteristics of the steady state specific to each selected country or group of countries. This study seems to be important in West Africa because it help to examining the validity of neoclassical assumption of convergence of poor and less poorer countries to a common steady state as well as examining if poor countries are converging faster than the richer ones in West Africa. It also investigates how important is the initial income in determining steady state and its characteristics.

To achieve the objective of this study, the basis of the analysis of $\beta$-convergence between different countries is put forward. A quantitative analysis inspired by the convergence model proposed by Maddala and Wu (2000) is carried out. The model is based essentially on the assumption of convergence of a country or a group of countries towards its own stationary state. Results are used to provide recommendations to the concerned countries.

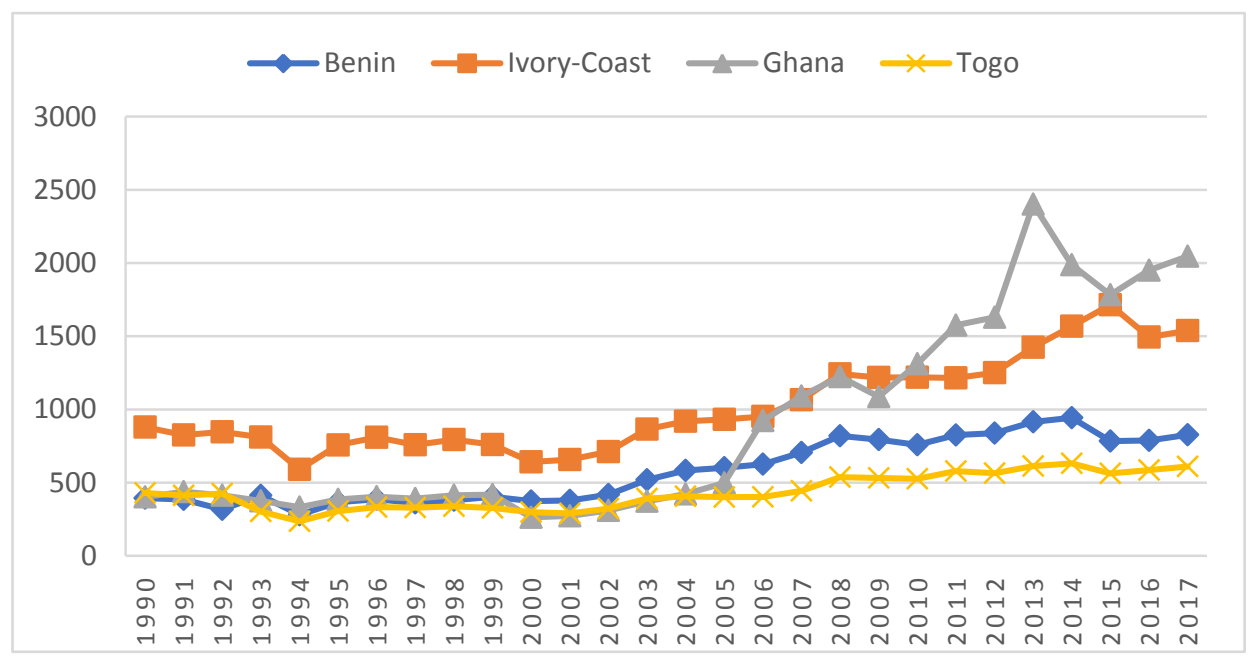

Figure 1. GDP Per Capita, 1990-2017 (current US\$)

Source: Author elaboration based WDI 2019

\section{Literature Revue}

Convergence is one of the important subjects in economic growth analysis. Thus, many authors have tried to answer questions such as: Do inequalities between countries reduce as time goes? Are all countries converging to a same level of income? What is the importance of

\footnotetext{
${ }^{4}$ UEMOA (or WAEMU): West African Economic and Monetary Union involves 8 member countries which are Benin, Burkina Faso, Côte D'Ivoire, Guinea-Bissau, Mali, Niger, Senegal, and Togo.

5 ECOWAS: Economic Community of West African States
} 
initial income in the explanation of current or countries' future incomes? Many studies have been devoted to these or similar questions without reaching a consensus. But for a better understanding of why all this interest to the subject, it is important to know what convergence is about and how economists measure it.

Many aspects of convergence have appeared in the economic literature. Among them, include the terms of $\sigma$-convergence, absolute $\beta$-convergence or conditional $\beta$-convergence. Neo-classical growth theories are famous for their optimistic prediction. They predicted an absolute convergence of countries based on the diminishing returns to capital. Thus, economies are predicted to converge to the same steady state. This is mainly due to the fact that; less developed economies are assumed to grow faster than the richer ones. This also holds when countries' preferences and technologies are taken into consideration (Barro, \& Sala-i-Martin, 1992). Barro and Sala-i-Martin's approach is based more on conditional convergence of countries. Canova, \& Marcet (1995) made a typology of convergence concept based on different theories. They define $\beta$-convergence as the situation in which countries with low income grow faster than higher income ones. It is called conditional convergence because it takes into account countries' specific characteristics. However, conditional $\beta$-convergence does not necessarily mean the absence of persistent inequalities between economies. $\sigma$-convergence occurs when there is reduction of dispersion between countries' incomes (see Canova, \& Marcet, 1995, Martin, \& Sunley, 1998). But still the limit between $\beta$-convergence and $\sigma$-convergence is tiny as the first phenomenon is a necessary condition to get the second one ( $\sigma$-convergence). Canova and Marcet also exposed the Bernard and Durluf's idea of unit root convergence which is of interest when testing convergence between two economies.

One of the interesting terms which have emerged from convergence analysis is the concept of club convergence. This concept should not to be confused with conditional convergence. Convergence club explains that a group of countries converge to a similar steady state based on some common characteristics among them (Beylunioğlu et al., 2018). Even though this concept may seem to be based on countries' geographical position, with time it has been defined more widely. Thus, the main idea behind this concept is that the neoclassical convergence seems not to happen. Rather, countries with same levels of development, same initial revenues or similar institutions tend to converge to the same steady state (Fischer, \& Stirböck, 2004).

Many empirical studies concerning convergence have been carried out and among them are studies by Barro et al. (1991), Mankiw et al. (1992), Barro \& Sala-i-Martin (1992), Durlauf \& Johnson (1995), Bernard \& Durlauf, (1995) .... Mankiw et al. (1992) and Barro (1995) tend to confirm the neo-classical view of negative relationship between the level of per capita income and the rate of growth, but the lower the obtained rate is, the more it reinforces the notion of conditional convergence. According to Barro et al. (1991) European countries and the US converge to a similar steady stage at the average converging rate of $2 \%$. Islam (1995) by using panel data in convergence analysis takes into account the bias relative to the cross-section analyses used by the previous studies. He reaches the conclusion that using panel data improve conditional convergence rate. He shows the important role played by 
technology and institution in countries' convergence patterns. Also, introducing human capital in his model seems to have more effect in a cross-section model than in the cross-countries one.

In contrast to the proponents of the neoclassical theory, endogenous growth authors such as Romer, Rebelo and King have highlighted the fact that traditional neoclassical relationship between income and growth rate and the country patterns to steady state may actually be wrong (Islam, 1995). Rather they find no relationship or even positive initial income-growth nexus with persistence of differences between countries. Baumol (1986) mentions the terms of club convergence to shed light on the phenomenon of convergence occurring between industrial countries and not shared by under developed countries. Many other studies have tried to determine the existence or absence of group convergence. This has also triggered a lot of studies of regions or groups-based convergence. Quah (1996), confirmed Baumol's point of view and insisted on the widening of the gaps between rich and poor countries.

Fischer \& Stirböck (2004) propose another way of treating convergence issues which is different from the Barro's traditional approach. They confirmed heterogeneity in convergence path and steady state between European countries. They proposed a detection of convergence clubs based on spatial analysis where each club has its own steady state based on regional factors. Butkus et al. (2018) have shown the paradox of convergence in European regions. They find absolute convergence occurring in European countries. However, this seems to happen at country level not at regional one. These conclusions are similar to Mikulić et al. (2013) who also found non convergence in European Union at regional level. Ito (2017) studied convergence between Asian countries. He detected 3 differences convergence clubs according to their income levels and also analysed the dynamic of transition of a country from one group (or club) to another. Some other studies have been about convergence in African and Latin American regions. Barrios, et al. (2019) found four convergence clubs in Latin America. These clubs, determined endogenously by the model, converge to different steady state at different rates while some countries (Ecuador and Nicaragua) have been diverging over the period covered by the study.

In the specific context of Africa, Jones (2002) studied convergence in the Economic Community of West African States (ECOWAS) zone and reached to the conclusion that the whole zone is converging to a single steady state. However, poorer countries seem to converge at a slower rate compared to the richer ones. He also mentioned the occurring of $\sigma$-convergence in the zone. A similar study was carried out by Dramani (2010) in CFA zones (UEMOA and CEMAC). He concluded on the occurrence of convergence in the zone with some temporal conditional convergence effects. He also, mentioned the existence of club convergence based on countries' specificities such as oil production, natural resources or advantage in some agricultural products. Bah (2015) found occurrence of stochastic convergence in the UEMOA zone. Concerning the $\beta$-convergence, he found that countries such as Burkina Faso, Togo and Mali are converging to the zone's average while Niger and Senegal are negatively and positively diverging respectively. No evidence of convergence was found for the other countries. 


\section{Methodology}

To analyse the $\beta$-Convergence effect between countries, a linear model inspired by Maddala $\& \mathrm{Wu}(2000)$ is employed. The model is presented as follows:

$$
\ln \left(y_{i t}\right)=\alpha_{i}+\rho_{i} \ln \left(y_{i, t-1}\right)+\mu_{i t}
$$

Where $y_{i t}=Y_{i t} / Y_{t}$, with $Y_{i t}$ the output per worker for the $\mathrm{i}^{\text {th }}$ economy and $Y_{t}$ is the average output per capita for all individual in year t. $\mu_{i t}$ is the random disturbance term which is supposed to be independent and identically distributed (i.i.d), that is, it is normally distributed and non-correlated across individuals. The advantage of this model is that it allows for the determination of different values of $\alpha_{i}$ and $\rho_{i}$ across individuals. Here $\beta$, the convergence factor, is obtained by using the formula:

$$
\rho_{i}=\exp \left(-\beta_{i}\right)
$$

We can then easily derive the average and individual $\beta_{i}$. The values of $\beta_{i}$ is calculated for all West African countries and also for individual countries, namely Benin, Cote d'Ivoire, Ghana and Togo. Maddala \& Wu (2000), used a basic neoclassical growth model à la Cobb-Douglas with log utility function where the steady state depends on the model's parameters. The log-linearized notation of the dynamic system around the steady state can be written as following:

$$
\ln \left(Y_{t} / Y_{t-1}\right)=a-\left(1-e^{-\beta}\right)\left[\ln \left(Y_{t-1}\right)-g \cdot(t-1)\right]
$$

Where

$$
a=g+\left(1-e^{-\beta}\right) \ln \left(\hat{Y}^{*}\right)
$$

Equation (1) is derived from (2) after transformation.

In their paper, they used the empirical shrinkage Bayesian estimator. But to attempt our main goal which is to compare the convergence path, we decide to use the simple and traditional approach of ordinary least square (OLS) estimator (see Maddala and Wu, 2000, p.638; Butkus et al., 2018). Despite some bias which can be associated with this method, we believe that it is not a great concern which can affect the order of estimates since values of estimates from Bayesian approach for this study seem to be similar to those of the OLS. Thus, at countries level, individual equations are estimated while the pooled option is used to estimate equations at group levels. Countries or group of countries are considered to be converging to their steady state when the estimated value of $\rho_{i}$ is less than one $\left(\rho_{i}<1\right)$ (Canova, \& Marcet, 1995). This is due to the specification used by Maddala and $\mathrm{Wu}$, who instead of the traditional logarithm of revenue per capita $\ln \left(Y_{i}\right)$, introduce $\ln \left(y_{i}\right)$, in the model, where $y_{i}$ is the ratio of individual income per capita to the annual average income per capita of all countries in the group. Another advantage of this model is that it helps to determine the rate of convergence, the steady state and the half-life of the converging countries or group. 


\section{Macrothink}

Once $\rho_{i}$ is estimated, we can compute the traditional $\beta_{i}$, the rate of convergence, half-life and the steady state using the following formula (see Canova \& Marcet, 1995; Maddala and Wu, 2000; Mikulić et al., 2013; Butkuset al., 2018):

- The rate of convergence $\beta_{i}$ for the country or group $\mathrm{i}$,

- The steady state value,

$$
\beta_{i}=-\ln \left(\rho_{i}\right)
$$

- Half-life period ${ }^{6}$ value,

$$
s s_{i}=\frac{\alpha_{i}}{\left(1-\rho_{i}\right)}
$$

$$
h l=\frac{\ln (2)}{\ln (1+\beta)}
$$

These values are computed for only west African converging sub-regions in a first step to allow for checking of countries convergences. They have been computed for each of the four chosen countries to compare their convergence paths' characteristics.

Data used in this study come from WDI 2019. These data concerned west African countries. From the 17 countries that were included in the sample only four countries namely, Carbo Verde, Guinea, Guinea-Bissau, Liberia and Saint Helena were excluded because they had some missing data. The study covered the time period of 27 years (from 1990 to 2017). This period has been chosen because of non-availability of data series before 1990 .

\section{Results and Discussions}

\subsection{Growth Convergence between West African Countries}

Figure 2 (a), which plots average GDP per capita growth (PPP) from 1990-2017 on their per capita GDP on 1990, for all the 12 West African countries included in our sample doesn't show any sign of growth convergence between them. Rather this chart shows dispersion in the data and a weak tendency to growth divergence among the countries (see trendline slope on Figure 2 (a)). In other words, there is no evidence that poorer countries are growing faster than the richer ones in the studied region. Such evidence could have been shown by a negative slope of Figure 2 (a)'s trendline. A similar plot has been made for the four countries of particular interest in this study (Figure 2 (b)). Here the results are quite different. Plot (b) shows a relatively strong sign of convergence between these four countries. However graphical analyses do not provide enough evidence to confirm or reject the presence of convergence between the countries.

\footnotetext{
6، The half-life period is defined as the time necessary for the economies to cover half of the initial lag from their steady states" (Mikulić etal, 2013)
} 
(a)

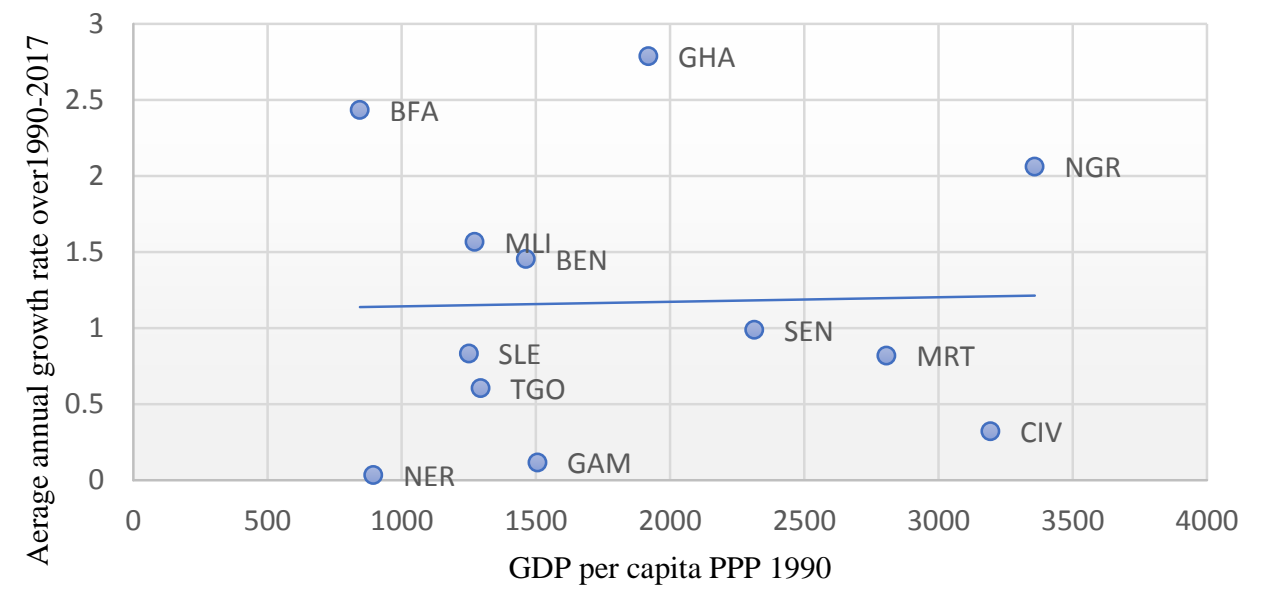

(b)

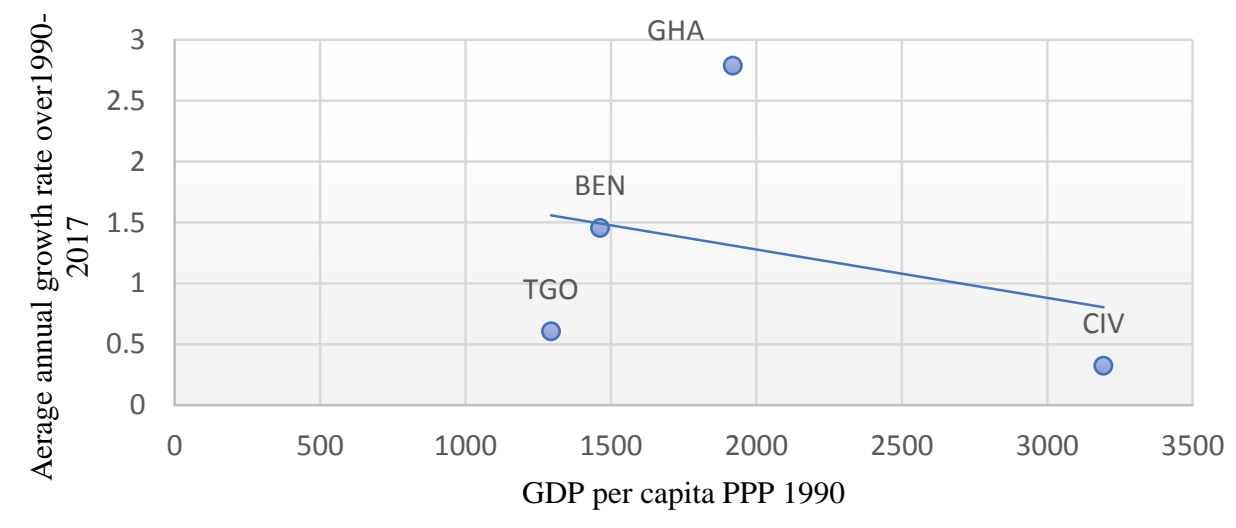

Figure 2. Per Capita average Growth and Initial GDP per capita

Source: Author's calculations based on WDI 2019

The econometric convergence model has been estimated with the pooled data of the 12 countries. The estimated $\rho$ parameter is about 1.001. This value of $\rho$ displayed in Table 1 , fits to the absence of convergence between countries shown by the Figure 2(a). This value of $\rho$ obtained from pooled estimation of the convergence econometric model is greater than zero, so we can conclude a non-convergence growth between the countries. we used the same approach for the small sample made up of Benin, Cote d'Ivoire Ghana, and Togo and the results show that the computed $\rho$ parameter, contrary to the evidence on Figure 2(b), does not confirm the existence of growth convergence between them. In fact, $\rho>1$ and it shows a divergence between countries' income level over the years. So, waiting for further analyses on the panel data, we can conclude on non-convergence in West African countries' growth as for the 4 countries' sub-group.

To get a better understanding of growth convergence in the region, we plotted the evolution of all the 12 countries' GDP per capita from the year 1990 to 2017. (see Figure 3). 


\section{MInstitute ${ }^{\text {Mink }}$}

Business and Economic Research

ISSN 2162-4860

2019, Vol. 9, No. 3

Observation of the chart shows that the 12 countries are not converging to the same points. From the observation of the plot, it appears that the countries can be categorized into two different groups. The first group (Club 1) consists of countries which have their initial GDP per capita less than US\$2000 (in 1990). These countries are Benin, Burkina Faso, Gambia, Mali, Niger, Sierra Leone, and Togo. They have the lowest per capita GDP in the group and seem to converge to the same point. The second group (Club 2) comprises Cote d'Ivoire, Ghana, Mauritania, Nigeria, and Senegal. Their GDP per capita are above US\$ 2000 and also seem to have their income converging to the same point. These observations let appear the probable existence of two different convergence clubs within West Africa. We can also pay attention to the cases of Niger and Nigeria which seem to be outliers. Niger at the bottom of the plots doesn't really seem to converge with other low-income countries. Similarly, Nigeria, which is at the top doesn't also seem to converge to the same point with other countries.

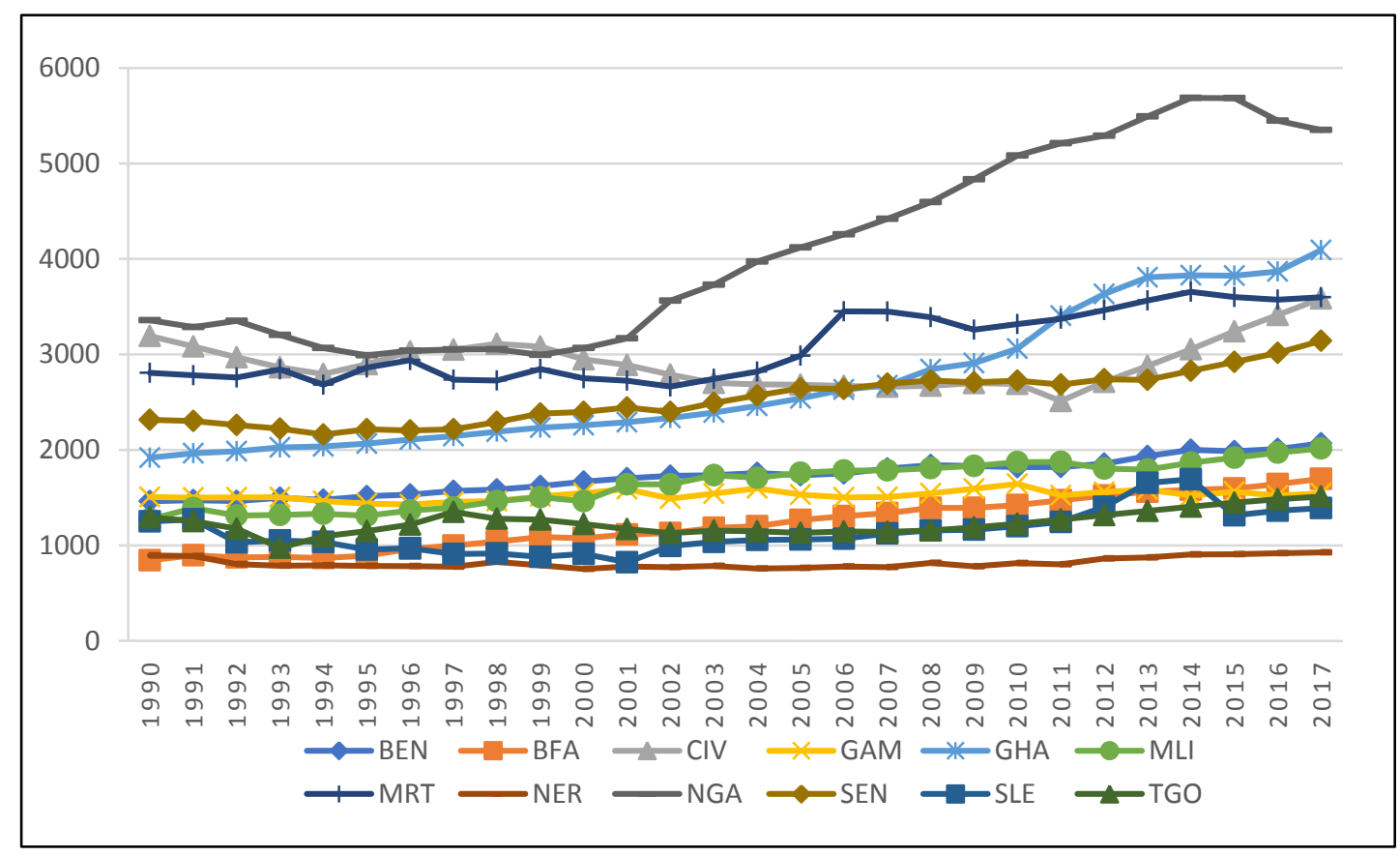

Figure 3. West African countries GDP per Capita PPP, 1990-2017

Source: Author's calculations based on WDI 2019

Thus, to verify these observations we divided the panel into two different groups: club 1 and Club $2^{7}$. We re-run the convergence equation with these new panels. We did the same thing with the two groups after excluding Niger (Club 1n) and Nigeria (Club 2n), respectively, from the $1^{\text {st }}$ and the $2^{\text {nd }}$ group. The results of our regression together with computed convergence rates, half-life and steady state of each group are displayed in Table 1.

As expected, club 1 which consists of countries with low per capita income has a steady state lower than that of club 2 (see Table 3. 1). This is normal because the model used here is based on the assumption that each country or group of countries converge to its own steady state

6initial lag from their steady states" (Mikulić etal, 2013)

Sierra Leone and Togo. Club 2 includes Cote d'Ivoire, Ghana, Mauritania, Nigeria and Senegal. Club 1n includes countries of club 1 except Niger. Club 2 includes countries of club 2 except Nigeria. 
(Maddala \& Wu, 2000). So, a group of countries with low income is expected to have a lower steady state compared to the others under certain conditions. The negative sign of steady state obtained for some groups or some countries means that these entities at their steady state have an per capita income lower than the average per income of the studied countries while negative value of $\alpha$ means that the initial income is lower than the average in the region. Club 1 convergence rate is $1 \%$ while club 2's is $1.81 \%$. These convergence rates are low and even lower than the $2 \%$ rate obtained by Barro et al. (1991) for the US and European countries. These findings can be explained by the high heterogeneity of the countries in terms of their initial income (Butkus et al., 2018). Countries in the first group grow slower than countries in the second group and this will be true even after reaching their study state (steady state $<0$ ). Considering the fact that the rate of convergence of club 1 to its steady state is low, it will take them more time to close half of their gap to it. So, club 1 half-life is more than 70 years while club 2 will have to spend about 40 years. But what happens to these statistics when we remove outliers from the sample?

Table 1. Estimation results and groups' convergence paths

\begin{tabular}{|l|c|c|c|c|c|c|}
\hline Countries & Number of countries & $\alpha$ & $\rho$ & Convergence rate & Half-Life & Steady state \\
\hline Panel 1 & 12 & -0.001 & 1.001 & & & \\
\hline Panel 2 & 4 & 0.003 & 1.001 & & & \\
\hline Club 1 & 7 & -0.007 & 0.990 & 1.00 & 70.525 & -0.739 \\
\hline Club 1n & 6 & -0.016 & 0.962 & 3.83 & 18.465 & -0.421 \\
\hline Club 2 & 5 & 0.008 & 0.982 & 1.81 & 38.608 & 0.468 \\
\hline Club 2n & 4 & 0.019 & 0.939 & 6.28 & 11.388 & 0.320 \\
\hline
\end{tabular}

Source: Estimates and author's calculation based on estimated parameters

Note: ${ }^{(a)}$ sample includes all the 12 countries taken into account in the study. ${ }^{(b)}$ Benin, Cote d'Ivoire, Ghana and Togo.

After removing Niger from club 1, we can notice a higher convergence rate and steady state (see club1n in Table 1). Thus, from $1 \%$ of the rate of convergence, club 1n converge more speedily (about $4 \%$ ) and its steady state changed from -0.739 to -0.421 . This is shown on the Figure 4. This can be explained by the fact that the too low level of Niger's per capita income has a great impact on the group steady state and increases its half-life period. Thus, from 70 years for club 1, excluding only Niger help to get a much lower time period of 18 years. In the other hand, excluding Nigeria from club 2 has the quite opposite effect of the one previously described (see club $2 \mathrm{n}$ in Table 1 ). In fact, in the opposite way of Niger 's case, Nigeria relatively high income per capita led to a high steady state. It makes harder for the group to reach this level. So, it took longer to reach a steady state. But removing Nigeria helps to get a lower steady state (0.320). The group becomes more homogenous, so it takes less time (about 11 years against 38 for club 2) and the rate of convergence became higher. 


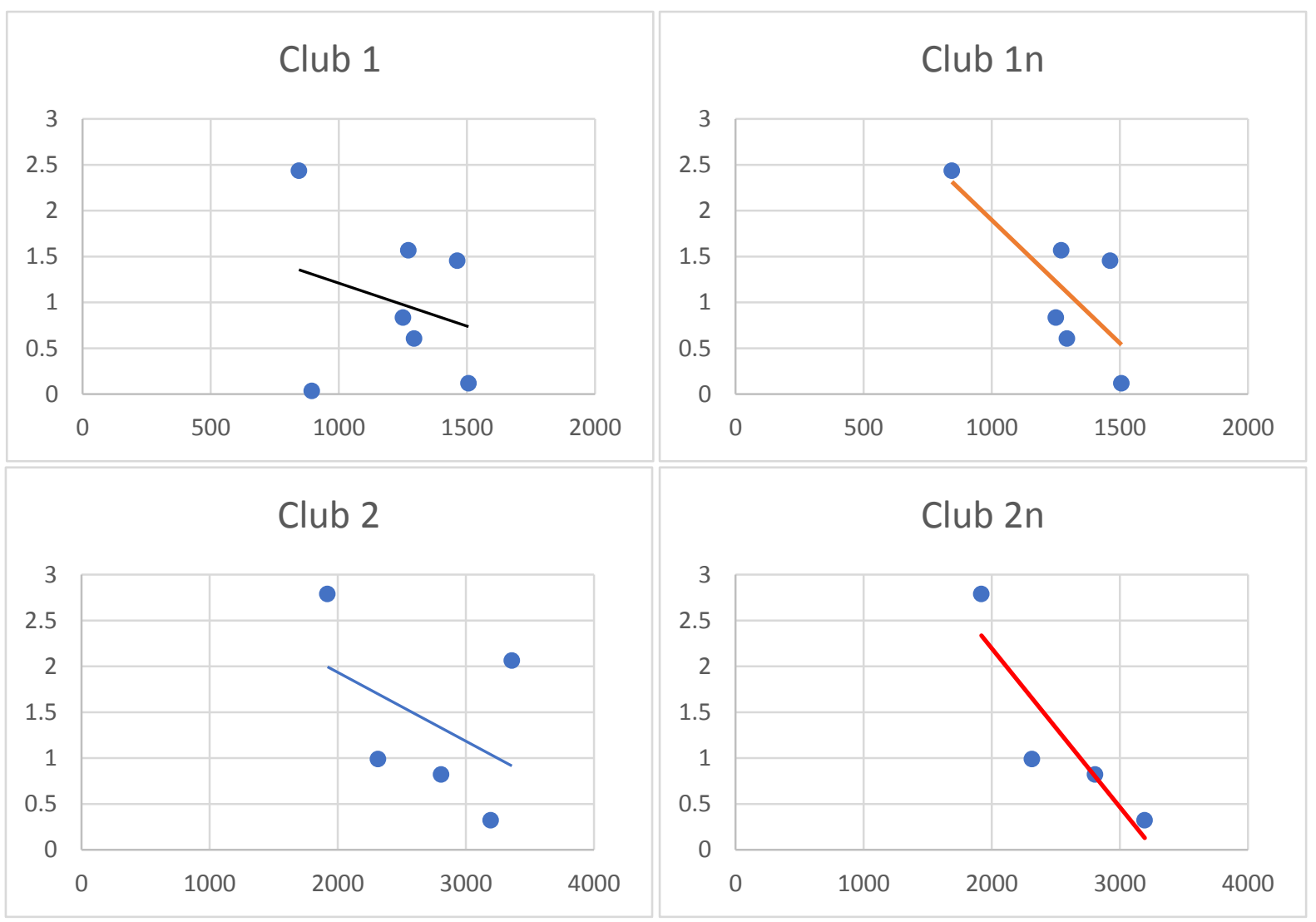

Figure 4. Per Capita average Growth and Initial GDP for convergence clubs

Source: Author's calculations based on WDI 2019

The non-validity of neoclassical assumption can be noticed here. In fact, West African data reject the possibility for countries to converge to the same steady state. Indeed, the group with higher initial income converges to a higher steady state and at a higher rate compared to the group with lower initial income. These results are similar, to some extent, to Canova \& Marcet (1995) who found that poor countries converge to lower steady state while rich countries converge to a higher steady state. Also, even though this assumption is right for constituted sub-groups low income countries don't converge faster than higher income ones. This is true even though poor countries are settled to converge to a lower steady state. These observations imply some useful conclusions for the next section. (a) we can conclude on the existence of club convergence (Quah, 1996, Durlauf \& Johnson, 1995) in West African economies. (b) Convergence path in West Africa is quite disturbed by individual country income level. Remark (a) explains the absence of evidence of convergence between Benin, Cote d'Ivoire, Ghana and Togo since they are not in the same convergence group. Also, it justifies the absence of convergence obtained by estimating convergence equation on the four countries' panel data. Remark (b) justify the next step of our work which consists of the individual estimation of convergence equation for each of these four countries.

\subsection{The Paths to the Steady States of Benin, Cote d'Ivoire, Ghana and Togo}

The previous section shows that West African countries are not all converging to the same 
steady state. Rather they are converging to two different steady state according to their initial income. We also noticed that Benin and Togo are in the first group while Cote D'Ivoire and Ghana are in the second group. This could explain why we got no evidence of convergence between these four countries. we then decide to analyse convergence path of these countries with the assumption that each of them is converging to its own steady state.

Table 2. Estimation results and countries' individual convergence paths

\begin{tabular}{|l|c|c|l|l|l|}
\hline Country & $\alpha$ & $\rho$ & Convergence rate & Half-Life & Steady state \\
\hline Benin & -0.013 & 0.918 & 8.52 & 8.474 & -0.165 \\
\hline Cote d'Ivoire & 0.014 & 0.939 & 6.34 & 11.277 & 0.224 \\
\hline Ghana & 0.020 & 0.984 & 1.64 & 42.542 & 1.202 \\
\hline Togo & -0.103 & 0.807 & 21.43 & 3.570 & -0.535 \\
\hline
\end{tabular}

Source: Estimates and author's calculation based on estimated parameters

Table 2, below, displays the estimates from the growth convergence model. It also includes computed values of convergence rates, half-life and steady states for Benin, Cote d'Ivoire, Ghana and Togo. First, we can notice different values of these parameters across the countries. Benin and Togo, the two smallest countries in the sample have the lowest steady states. But this is related to their lower initial per capita income and not to their size. The negative values of their steady states mean that their steady-state incomes are lower than the West African average steady-state income. It, also, means that at their steady states, they will grow slower than the average rate. However, Togo's steady state is higher than that of Benin. The values of half-life obtained for these two countries are quite different too. In fact, while Benin has a half-life of about 8.5 years, Togo's is almost half of it, which is about 3.5 years. These differences in time spent in closing half of the gaps to the steady state are also partially due to the pace of convergence of these countries. In fact, Benin converges at a rate of 8,52\% while Togo converges at a higher rate which is above $21 \%$ (see Table 2.). But these two countries' situations seem to be the opposite of those of their bigger neighbours such as Cote d'Ivoire and Ghana. It may be due to the previously highlighted reasons.

Cote d'Ivoire and especially Ghana, converge to their study states at a relatively low rate. Ghana has the lowest convergence rate in the group (1.64), while that of Cote d'Ivoire is above $6 \%$. Ghana, compared to the other countries, has a very high steady state and then will grow at a high rate once this level is reached. Finally, Ghana's half-life is also large compared to the others. Thus, while Togo needs about 3.5 years to get to the halfway of its steady state, Benin needs 8.5 years and Cote d'Ivoire 11.27, Ghana needs about 42.50 years. In terms of convergence rate and half-life Benin's situation seems to be more similar to that of Cote d'Ivoire. These results indicate the great difference in growth paths of these selected countries despite their social, geographical and cultural similitudes. Contrary to the tendencies at groups level, Table 2 shows that poor countries are converging faster to their steady state than richer ones. But here is important to recall one important assumption of our model: each country is converging to its own steady state. And as we can see, the obtained steady states for the countries are quite different. These observations make it hard to confirm neoclassical convergence prediction when it comes to West African countries. 


\section{Conclusion}

The countries of West Africa, despite the fact that they all belong to the group of developing countries, do not seem to confirm the predictions of the neoclassical theory on the convergence of economies towards the same level of income. This paper studies the convergence process in West Africa over the period 1990-2017, with a focus on Benin, Cote d'Ivoire, Ghana, and Togo. It aims to check whether the countries in the regions are converging to the same income level. To this end, a quantitative analysis inspired by the convergence model proposed by Maddala and $\mathrm{Wu}$ (2000) was carried out. We based our analyses on the assumption of convergence that all the countries converge to a unique steady state.

Results show that West African countries are not converging to the same steady state. Two convergence groups have been detected: one is composed of countries with high initial income per capita and the other with countries having low initial per capita income. These results allow us to conduct our analyses at individual countries level. Thus, by focuses on the case of Benin, Cote d'Ivoire, Ghana and Togo, results shed light on the fact that countries with similar characteristics may actually have different growth patterns. Ghana and Cote d'Ivoire have higher steady states while Benin and Togo (having lower income per capita), converge to lower steady states. However, Benin and Cote d'Ivoire, although having different steady-states, seem to exhibit similar rates of convergence.

This study contributes to the literature by showing that convergence process is not homogenous across West African countries and this should be taken into account by policymakers when designing common economic policies in the region. In fact, most of the economic policies in the region have been implemented without taken into account this issue. To facilitate the process of integration within the region, countries' heterogeneity and countries characteristics should be considered. As the study emphasises the role of initial income, further analyses of other factors could help to understand what determine countries' income levels in the region. Also, this study does not take in consideration $\sigma$-convergence which is important in understanding growth dynamic between countries. Future studies on this subject could look into this issue.

\section{References}

Bah, M. S. (2015). Real convergence in West African Economic and Monetary Union (WAEMU). Economics Letters, 135, 19-23. https://doi.org/10.1016/j.econlet.2015.07.020.

Barro, R. J., Sala-i-Martin, X., Blanchard, O. J., \& Hall, R. E. (1991). Convergence across states and regions. Brookings papers on economic activity, 107-182.

Barro, R. J., \& Sala-i-Martin, X. (1992). Convergence. Journal of political Economy, 100(2), 223-251. https://doi.org/10.1086/261816

Baumol, W. J. (1986). Productivity growth, convergence, and welfare: what the long-run data show. The American Economic Review, 1072-1085.

Bernard, A. B., \& Durlauf, S. N. (1995). Convergence in international output. Journal of 
applied econometrics, 10(2), 97-108. https://doi.org/10.1002/jae.3950100202.

Beylunioğlu, F. C., Yazgan, M. E., \& Stengos, T. (2019). Detecting Convergence Clubs. Macroeconomic Dynamics. https://doi.org/10.1017/S1365100518000391

Butkus, M., Cibulskiene, D., Maciulyte-Sniukiene, A., \& Matuzeviciute, K. (2018). What Is the Evolution of Convergence in the EU? Decomposing EU Disparities up to NUTS 3 Level. Sustainability, 10(5), 1552. https://doi.org/10.3390/su10051552

Canova, F., \& Marcet, A. (1995). The poor stay poor: Non-convergence across countries and regions.

Dramani, L. A. (2010). Convergence and economic integration in Africa: The Case of the Franc zone countries.

Durlauf, S. N., \& Johnson, P. A. (1995). Multiple regimes and cross - country growth behaviour. Journal of applied econometrics, 10(4), 365-384.

Fischer, M. M., \& Stirböck, C. (2004). Regional income convergence in the enlarged Europe, 1995-2000: a spatial econometric perspective. ZEW-Centre for European Economic Research Discussion Paper, (04-042). https://doi.org/10.2139/ssrn.560882

Islam, N. (1995). Growth empirics: a panel data approach. The Quarterly Journal of Economics, 110(4), 1127-1170. https://doi.org/10.2307/2946651

Ito, T. (2017). Growth convergence and the middle-income trap. Asian Development Review, 34(1), 1-27. https://doi.org/10.1162/ADEV_a_00079

Jones, B. (2002). Economic integration and convergence of per capita income in West Africa. African Development Review, 14(1), 18-47. https://doi.org/10.1111/1467-8268.00044

Maddala, G. S., \& Hu, W. (1996). The pooling problem. In The econometrics of panel data (pp. 307-322). Springer, Dordrecht. https://doi.org/10.1007/978-94-009-0137-7_13

Maddala, G. S., \& Wu, S. (2000). Cross-country growth regressions: problems of heterogeneity, stability and interpretation. applied Economics, 32(5), 635-642. https://doi.org/10.1080/000368400322534

Mankiw, N. G., Romer, D., \& Weil, D. N. (1992). A contribution to the empirics of economic growth. The quarterly journal of economics, 107(2), 407-437.

https://doi.org/10.2307/2118477

Martin, R., \& Sunley, P. (1998). Slow convergence? The new endogenous growth theory and regional development. Economic geography, 74(3), 201-227. https://doi.org/10.2307/144374

Mikulić, D., Lovrinčević, Ž., \& Nagyszombaty, A. G. (2013). Regional convergence in the European Union, new member states and Croatia. South East European Journal of Economics and Business, 8(1), 9-21. https://doi.org/10.2478/jeb-2013-0001

Quah, D. T. (1996). Empirics for economic growth and convergence. European economic review, 40(6), 1353-1375. https://doi.org/10.1016/0014-2921(95)00051-8 


\section{Macrothink}

Business and Economic Research

ISSN 2162-4860 2019, Vol. 9, No. 3

The World Bank, 2019, World Bank Country and Lending Groups [online] Available: https://datahelpdesk.worldbank.org/knowledgebase/articles/906519 (May 20, 2019)

UNDP (2018). Human development indices and indicators: 2018 Statistical update.

\section{Copyright Disclaimer}

Copyright for this article is retained by the author(s), with first publication rights granted to the journal.

This is an open-access article distributed under the terms and conditions of the Creative Commons Attribution license (http://creativecommons.org/licenses/by/3.0/). 